Çukurova Üniversitesi Mühendislik Mimarlık Fakültesi Dergisi, 33(4), ss. 1-8, Aralık 2018

Çukurova University Journal of the Faculty of Engineering and Architecture, 33(4), pp. 1-8, December 2018

\title{
Bir Güneş Havuzundan Üretilecek Elektrik ile Hidrojen Elde Etme Sisteminin Performansının Teorik Olarak İncelenmesi
}

\author{
Ayhan ATIZ1, Mehmet KARAKILÇIK ${ }^{* 2}$ \\ ${ }^{1}$ Alanya Alaaddin Keykubat Üniversitesi, Eğitim Fakültesi, İlköğretim Matematik ve Fen \\ Bilimleri Bölümü, Antalya \\ ${ }^{2}$ Çukurova Üniversitesi, Fen Edebiyat Fakültesi, Fizik Bölümü, Adana
}

Geliş tarihi: 06.03.2018 Kabul tarihi: 25.12.2018

$\ddot{\mathbf{O} z}$

Bu çalışmada, dikdörtgen prizma tuz eğimli güneş havuzu (DPTEGH)'nun elektrik ve hidrojen üretim performansı incelendi. Güneş enerjisinden 1sı enerjisi üretmek için $1,5 \times 8 \times 8 \mathrm{~m}^{3}$ boyutunda dikdörtgen prizma şeklinde bir güneş havuzu, Organik Rankine Çevrimi (ORÇ) ve elektroliz sisteminden oluşan bir birleşik sistem tasarlandı. Tasarlanan bu sistemin analizi mühendislik eşitlikleri çözücü (EES) benzetim programı kullanılarak gerçekleştirildi. Havuzda depolanan 1sı enerjisi Organik Rankine Çevrimi (ORÇ)'ye aktarıldı. Böylece, başarılı bir şekilde depolanan 1sı enerjisi kullanılarak ORÇ'de elektrik üretildi. Ancak, hem ısının hem de elektriğin verimli bir şekilde depolanamaması yüzünden, üretilen enerji bir elektroliz sisteminde hidrojen üretiminde kullanıldı. Böylece suyun elektrolizi ile hidrojen gazı üretildi. Analizler, Haziran, Temmuz, Ağustos ve Eylül ayları için ayrı ayrı yapıldı. Sonuç olarak, ORÇ'nin enerji verimi Haziran Temmuz, Ağustos ve Eylül ayları için sırasıyla \%16,20, \%16,73, 17,47 ve $\% 15,32$ olarak bulundu. Aynı aylar için üretilen elektrik ise sırasıyla, 143,2 MJ, 156,2 MJ, 168,5 MJ ve 130,5 MJ olarak hesaplandı. Bu elektriğin, bir elektroliz sisteminde kullanılmasıyla da sırasıyla 1,216 kg, $1,326 \mathrm{~kg}, 1,431 \mathrm{~kg}$ ve $1,108 \mathrm{~kg}$ hidrojen üretilebileceği görüldü.

Anahtar Kelimeler: Güneş enerjisi, Güneş havuzu, Organik rankine çevrimi, Elektrik ve hidrojen üretimi

\section{The Theoretical Investigation of Performance of the Hydrogen Attaination System with Electricity from a Solar Pond}

\begin{abstract}
In this study, the electricity and hydrogen production performance of the rectangular prism salt sloped solar pond (RPSSSP) was examined. In order to generate thermal energy from solar energy, an integrated system consisting of a solar pond in the form of a rectangular prism of $1.5 \times 8 \times 8 \mathrm{~m}^{3}$, Organic Rankine Cycle (ORC) and electrolysis system was designed. The analysis of the designed system was carried out using an engineering equations solver (EES) program. Thermal energy stored in the pond was transferred to the Organic Rankine Cycle. Thus, electricity was generated in the ORC by using thermal energy, successfully. However, due to the fact that both heat and electricity cannot be efficiently stored, the energy produced is used in the production of hydrogen in an electrolysis system. Hydrogen gas was
\end{abstract}

*Corresponding author (Sorumlu yazar): Mehmet KARAKILÇIK, kkilcik@cu.edu.tr 
produced by electrolysis of water. The analysis was done separately for June, July, August and September. As a result, the energy consumption of the ORC was $16.20 \%, 16.73 \%, 17.47 \%$ and $15.32 \%$ for June July, August and September respectively. Electricity generated for the same months was 143.2 MJ, 156.2 MJ, 168.5 MJ and 130.5 MJ, respectively. By using this electricity in an electrolysis system, $1.216 \mathrm{~kg}, 1.326 \mathrm{~kg}, 1.431 \mathrm{~kg}$ and $1.108 \mathrm{~kg}$ of hydrogen can be produced, respectively.

Keywords: Solar energy, Solar pond, Organik rankine cycle, Electric and hydrogen production

\section{GíRIŞ}

Günümüzde enerji ihtiyacı her geçen gün daha da artmaktadır. Artan enerji ihtiyacı ve fosil yakıtların yenilenemez olması ve çevreye zarar vermesinden dolayı yenilenebilir enerji kaynaklarına doğru yoğun çalışmalar başlamıştır. $\mathrm{Bu}$ nedenle dünya temiz ve yenilenebilir enerji kaynaklarına doğru yönelmeye başladı. Bu kaynaklar temiz ve sürekli olduklarından onlardan enerji elde edilmesi oldukça önemli bir hale gelmiştir [1]. En önemli yenilenebilir enerji kaynaklarından birisi güneş enerjisidir. Güneş enerjisinden yararlanarak 1s1 depolaması yapan önemli sistemlerden birisi güneş havuzlarıdır. Güneş havuzları, iyi 1sı depolayan sistemlerinden biridir. İç bölgelerdeki güneş havuzunun her katının sıcaklığı, giren güneş radyasyonuna, tabaka kalınlıklarına, bölgelerin gölgeleme alanlarına ve genel ısı kaybına bağlıdır. Tabaka kalınlıklarının değiştirilmesi havuz performansını ve havuzun kararlılığını arttırır [2]. Güneş havuzlarının 1sı depolama kapasitesi dolayı bu sistemden 1sı çekilmesi mümkündür. Sürdürülebilir 1Sı enerjisi kaynağı olarak güneş havuzlarından yaralanabilir. Hem deneysel hem de teorik olarak bu mümkündür [3]. Güneş havuzu üç tabakadan oluşmaktadır. Bunlar; üst isı yayma bölgesi, yalıtım bölgesi ve depolama bölgesidir. Havuzun yalıtım bölgesi ve depolama bölgesinden 1S1 çekildiğinde havuzun depoladığı 1S1 daha verimli kullanılmaktadır [4]. Güneş havuzlarının depolama bölgesinde var olan bu 1S1 kapasitesinden yararlanarak elektrik üretildiği birçok çalışma gösterilmiştir. Bu çalışmaların birisinde üretilen elektik miktarı 5000 MW'a kadar çıkmıştır [5]. Düşük 1sı enerjisinden yararlanarak elektrik üretimi için kullanılan sistemlerden biri Organik Rankine Çevrimi (ORÇ)'dir [6]. Bir güneş havuzu ve düzlemsel toplayıcılardan oluşan sistemde yüksek sıcaklıkta su elde edilir. Isı dönüştürücüsünden yararlanarak ORÇ'ye sıcak su gönderilmiştir. $\mathrm{Bu}$ sıcak suyun 1sı enerjisinden yararlanarak ORÇ'de elektrik üretimi gerçekleşmiştir. Üretilen bu elektrik ise elektroliz için de kullanılarak hidrojen enerji üretimi için kullanılmıştır. $\mathrm{Bu}$ üretim mühendislik eşitlikleri çözücü (EES) benzetim programı yardımıyla yapılmıştır [7]. Elektroliz teknolojisi, elektrokimyasal reaksiyonlar yoluyla hidrojen üretmek için etkili ve pratik bir yöntem olarak kabul edilir [8]. Hidrojen enerji sistemleri temiz, güvenilir, uygun fiyatlı, güvenli ve sürdürülebilir akıllı enerji çözümleri parçası olma potansiyeline sahiptir. Hidrojenin, fosil yakıtlarla birlikte nükleer güç, biyokütle ve yenilenebilir enerji gibi çeşitli kaynaklardan üretilebilmesidir. Böylece Dünya benzeri görülmemiş enerji sorunları ile karşı karşıya olduğundan, birçok ülke, sürdürülebilir bir geleceğe ulaşmak için akıllı enerji çözümlerinden biri olan hidrojeni kullanabilir [9]. Hidrojen enerjisi, sistemlerde fazla üretilen elektriği depolayarak daha sonra kullanılmak üzere kullanılabilecek son derece önemli bir kaynaktır [10]. Bu kaynaklardan biri olan güneş enerjisinden yararlanarak hidrojen üretimi yapmak hem temiz hem de sürdürülebilir hidrojen üretimi için son derece önem arz etmektedir [11].

Yukarıdaki çalışmalarda görüldüğü gibi, güneş enerjisinden yararlanarak bütünleşmiş sistemlerde 1S1 enerjisi üreterek hidrojen üretmek mümkündür. Bunun için bu sistemde güneşten yararlanan bir güneş havuzu ORÇ'ye bütünleştirilmiştir. $\mathrm{Bu}$ sistemin en önemli özelliği ise, üretilen 1s1 enerjisi sadece güneş havuzundan gönderilmiştir. Böylece düşük sıcaklarda Adana çevre koşullarında daha önce yapılmayan dikdörtgen bir güneş havuzunun hidrojen üretim performansı incelenmiştir. Hidrojen üretimi için güneş havuzunda depolanan 1s1 enerjisi bir pompa yardımıyla ORÇ’ye gönderilerek elektrik üretimi olmuştur. Böylece üretilen elektrikten yararlanarak elektrolizde 
hidrojen gazı üretimi yapılmıştır. $\mathrm{Bu}$ tarz çalışmalar artırılarak geleceğin enerjilerinden biri olan hidrojen üretiminin çeşitlendirilmesi amaçlanmıştır. Bu çalışma için Adana'da güneş havuzunda 1sı enerjisinin en fazla depolanabildiği, Haziran, Temmuz, Ağustos ve Eylül ayları için sistem çalıştırılmıştır. Bu çalışmada, mühendislik alanında kabul görmüş EES benzetim programı kullanılmıştır. Yaz aylarında elde edilen hidrojen depolanarak daha sonra bir enerji kaynağı olarak kullanabileceği düşünülmüştür.

\section{SISTEM AÇIKLAMASI}

Şekil 1'de, bütünleşmiş sistemin bileşenleri görülmektedir. Bütünleşmiş üretim sistemleri enerji girdisinin mümkün olan en yüksek geri kazanımını sağlamak için farklı sistemlerin bütünleşmesiyle daha yüksek verim sağlar [12]. Bu bütünleşmiş sistemde güneş havuzu, 1s1 dönüştürücü, pompa, ORÇ ve elektroliz sisteminden oluşmaktadır. $\mathrm{Bu}$ sistemde en önemli bileşenlerinden birisi güneş havuzudur. Çünkü güneş havuzu gelen güneş enerjisini önemli bir kısmını kendi içerisinde depolamaktadır. Sistemdeki güneş havuzunun boyutları $1,5 \times 8 \times 8 \mathrm{~m}^{3}$ 'dir. Güneş havuzları üç bölgeden oluşmaktadır. Üst 1sı yayma bölgesi (ÜYB) temiz sudan oluşan bölgedir. $\mathrm{Bu}$ bölgenin kalınlığ 0,1 m'dir. Yalıtım bölgesi (YB) yoğunluğu depolama bölgesine doğru artan bölgedir. Bu bölge depolama bölgesindeki ısının hızlı şekilde dışarı çıkmasını engelleyen 1sı yalıtım bölgesidir ve kalınlığı 0,5 m'dir Depolama bölgesi (DB) güneş enerjisinin 1sı enerjisi olarak depolandığı bölgedir ve bu bölgenin kalınlığı ise 0,9 m'dir [13]. Bu sistemde pompal aracılığıyla ılık su havuzun depolama bölgesine gönderilir. Bu su DB'nden 1s1 dönüştürücü yardımıyla ısınarak ORÇ’ye gönderilir. ORÇ’ye gelen sıcak sudan yararlanan izobütan sıvısı pompa2 yardımıyla buharlaştırıcıda 1sınarak türbine gönderilir. Böylece türbin dönerek bir elektrik elde edilir. Bu döngü böyle devam eder. Sistemden üretilen bu elektrik elektroliz sistemine verilerek hidrojen elde edilir.

Bu sistem çalışmasında bazı kabuller yapılmıştır.

Güneş havuzunun çok iyi yalıtıldığı ve depolama bölgesi sıcaklığının güneş varken değişmediği kabul edilmiştir. Dört ay boyunca depolama bölgesi sıcaklığının $55^{\circ} \mathrm{C}$ olarak alınmıştır.

- Her ay için depolama bölgesinde depolanan 1s1 enerjisi bir 1S1 dönüştürücü yardımıyla \%90’1 kullanıldı.

- Türbin verimi ise, $\% 40$ alınmıştır.

- Çevre sıcaklığg ise, meteorolojiden alınan ortalama aylık sıcaklık değerleridir.

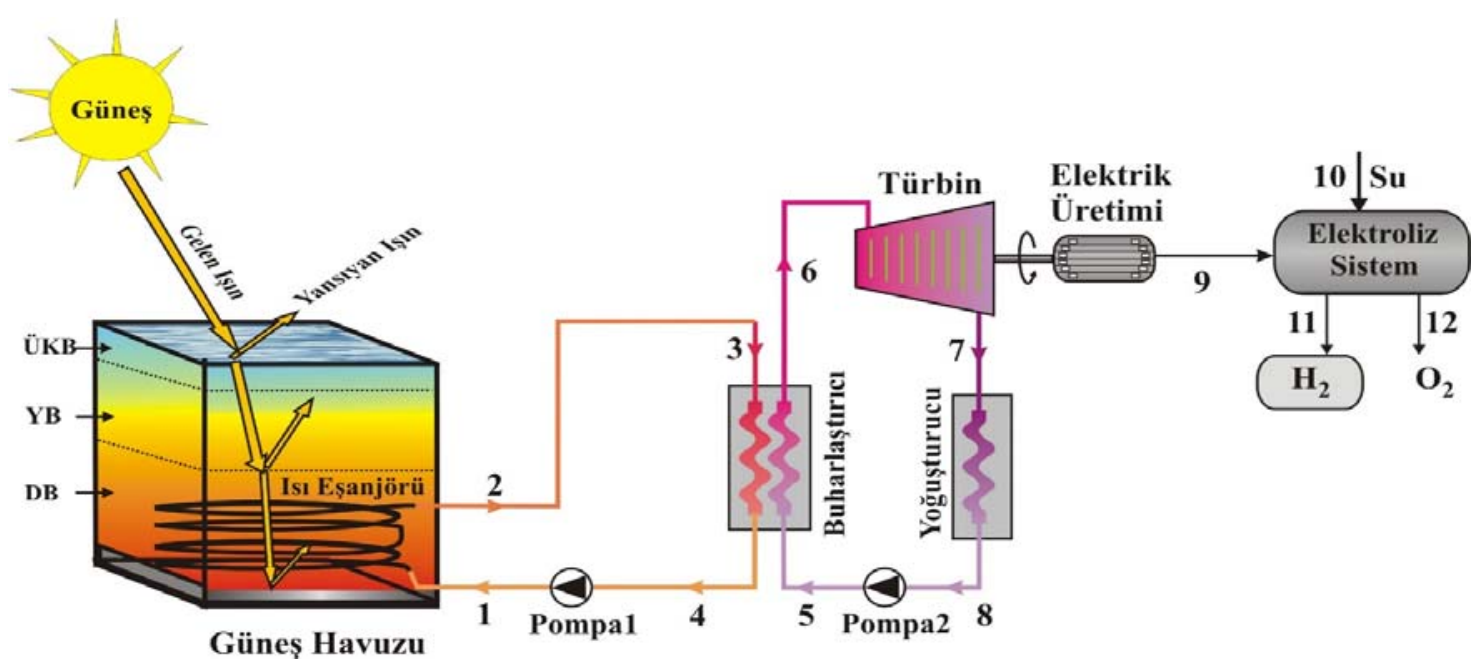

Şekil 1. Güneş havuzu ile bütünleşik hidrojen üretim sistemi 


\section{SISTEMIN ANALIZi}

Sistemin termodinamik analizinin yapilabilmesi için her bir bileşenin incelenmesi gerekir. Bunun için sistemdeki enerji dağılımlarının nasıl olduğunun belirlenmesi gerekir.

\subsection{Güneş Havuzu}

Güneş havuzunda gelen enerjinin depolandığı yer güneş havuzunun depolama bölgesidir. Sistemdeki enerjisi buradan temin edilmektedir. Güneş havuzunun depolama bölgesine ulaşan güneş aşağıdaki gibi bulunur [14].

$\dot{\mathrm{Q}}_{\mathrm{YB}}=\eta \mathrm{A}_{\mathrm{GH}} \mathrm{I}_{\mathrm{DB}}$

Burada $\eta$ güneş havuzunun depolama bölgesinin enerji verimidir. $\mathrm{I}_{\mathrm{DB}}$ havuzun depolama bölgesine gelen güneş enerjisi $\left(\mathrm{W} / \mathrm{m}^{2}\right)$ dir. $\mathrm{A}_{\mathrm{GH}}=64 \mathrm{~m}^{2}$ havuzun toplam yüzey alanını ifade etmektedir. Burada güneş havuzunun verimi gölgeleme alanı küçüldükçe verimi artmaktadır. Yaz ayları havuzun depolama bölgesi sıcaklığının $55^{\circ} \mathrm{C}$ ve üzerine çıkabildiği zamandır [14]. Güneş havuzunun yüzey alanı yeterince büyükse, gölgeleme etkisi oldukça azalacaktır [15]. Ayrıca, güneş havuzunun gölgelenme etkisi yanstıcı kapaklı güneş havuzlarında havuz yüzeyine gelen güneş enerji artırılabilir. [16]. Ancak bu çalışmada, gölgelemenin verim üzerindeki etkisi yok sayılmıştır. Haziran, Temmuz, Ağustos ve Eylül için depolama bölgesinin verimleri sırasıyla, $\% 29,03, \% 31,65, \% 37,25$ ve $\% 35,07$ olarak alınmıştır. $\mathrm{Bu}$ verimler gelen güneş enerjisinin yoğunluğu ve geliş açısı yüzünden değişmektedir.

\subsection{Isı Dönüştürücü}

Is1 dönüştürücü, birbirinden ayrılmış farklı sıcaklıklardaki iki akışkan arasında 1sı değişimini kolaylaştıran aygıtlardır İki akışkan arasındaki ısı aktarımı aşağıdaki elde edilir [17].

$\dot{\mathrm{Q}}_{\mathrm{TR}}=\mathrm{UA}_{\mathrm{y}} \Delta \mathrm{T}_{\mathrm{lg}}$

Burada, U bütün yüzey boyunca hem konveksiyon ve iletim yoluyla elde edilen isı transfer katsayısıdır. Bu çalışmada $\mathrm{U}=1000 \mathrm{~W} / \mathrm{m}^{2 \circ} \mathrm{C}, \mathrm{A}_{\mathrm{y}} 1 \mathrm{~s} 1$ transferi sağlayan metalin yüzeyi, $\Delta \mathrm{T}_{\mathrm{lg}}$ logaritmik sıcaklık fark aşağıdaki elde edilir.

$$
\begin{aligned}
& \Delta \mathrm{T}_{\mathrm{lg}}=\frac{\Delta \mathrm{T}_{1}-\Delta \mathrm{T}_{2}}{\operatorname{In}\left(\frac{\Delta \mathrm{T}_{1}}{\Delta \mathrm{T}_{2}}\right)} \\
& \Delta \mathrm{T}_{1}=\mathrm{T}_{\mathrm{DB}}-\mathrm{T}_{\mathrm{DB}, \mathrm{c}} \\
& \Delta \mathrm{T}_{2}=\mathrm{T}_{\mathrm{DB}}-\mathrm{T}_{\mathrm{DB}, \mathrm{g}}
\end{aligned}
$$

Burada $\mathrm{T}_{\mathrm{DB}}$ depolama bölgesinin sıcaklığıdır. $\mathrm{T}_{\mathrm{DB}, \mathrm{g}}$ ve $\mathrm{T}_{\mathrm{DB}, \mathrm{c}}$ ise havuzun depolama bölgesine gönderilen ve depolama bölgesinden ısınarak çıkan suyun sicaklığıdır. Yaz aylarında sıcaklık depolama bölgesi sıcaklığı gölgelemenin yüksek olduğu zamanda bile $\mathrm{DB} \quad 50{ }^{\circ} \mathrm{C}$ üzerine çıkabilmektedir. Yaz ayları dışında diğer aylarda 1S1 depolama bölgesinin sıcaklığ $50^{\circ} \mathrm{C}$ 'nin üzerine çıkmamaktadır [2]. $\mathrm{Bu}$ benzetim sisteminde havuzun depolama bölgesi sıcaklığı Haziran, Temmuz, Ağustos ve Eylül ayları için $55^{\circ} \mathrm{C}$ olarak alınmıştır.

\subsection{Organik Rankine Çevrimi (ORÇ)}

Organik Rankine Çevrimi, yüksek basınçlı bir sıvının buharlaşmasına dayanır ve bu da daha düşük bir basınca kadar genleşerek mekanik bir iş çıkarır. Çevrim, düşük basınçlı buharın yoğunlaştırılması ve onu yüksek basınçta pompalayarak kapatılır. $\mathrm{Bu}$ nedenle, Organik Rankine Çevrimi klasik bir buhar santrali (kazan, genleşme cihazı üreten bir iş, bir kondansatör ve bir pompa) ile aynı bileşenleri içerir [18]. Düşük dereceli 1sı kaynağı kullanan ümit vaat eden bir enerji dönüştürme teknolojisi olan ORÇ endüstriyel atık 1s1, güneş enerjisi, jeotermal enerji gibi düşük dereceli 1sı kaynağı kullanarak ayırt edici avantajları nedeniyle son yıllarda büyük bir araştırmanın odak noktası olmuştur. Birçok araştırmacı, ORÇ'nin termodinamik analizini ve performansının iyileştirilmesini yaparak veriminin artması için çalışmalar yapılmıştır [19]. ORÇ’nin içine giren suyun sıcaklığın $\left(\mathrm{T}_{3}\right) 50^{\circ} \mathrm{C}$ 'den yüksek olması ORC'nin daha verimli olmasını sağlar [20]. $\mathrm{Bu}$ çalışmada, bu yüzden $50^{\circ} \mathrm{C}$ 'den yüksek sıcaklık tercih edilmiştir. ORÇ'den elde edilen net güç aşağıdaki gibi ifade edilir. 
$\dot{\mathrm{W}}_{\text {net }}=\dot{\mathrm{W}}_{\mathrm{G}}-\left(\dot{\mathrm{W}}_{\text {pompa } 1}+\dot{\mathrm{W}}_{\text {pompa2}}\right)$

Burada $\dot{W}_{G}$ turbin jeneratör gücü, $\dot{W}_{\text {pompa1 ve }}$ $\dot{\mathrm{W}}_{\text {pompa2 pompalama güçleridir. }}$

$\dot{\mathrm{W}}_{\mathrm{T}}=\eta_{\mathrm{T}} \eta_{\mathrm{G}} \dot{\mathrm{m}}_{6}\left(\mathrm{~h}_{6}-\mathrm{h}_{7}\right)$

Burada $\eta_{\mathrm{T}}, \eta_{\mathrm{G}}, \dot{\mathrm{m}}_{6}, \mathrm{~h}_{5}$ ve $\mathrm{h}_{6}$ sirasıyla, türbin izentropik verimliliği, jeneratörün mekanik verimi, izobütan sıvısının döngüdeki kütle akış hızı, 6 ve 7 noktalarının entalpisidir. ORÇ'nin enerji verimi sistemde üretilen net elektriğin ile buharlaştırıcıya giren net enerjiye oranı olarak elde edilir. Böylece ORÇ'nin enerji verimi aşağıdaki elde edilir [21].

$\eta_{\mathrm{ORC}}=\frac{\dot{\mathrm{W}}_{\mathrm{net}}}{\dot{\mathrm{Q}}_{\mathrm{bh}}}$

Burada $\dot{\mathrm{Q}}_{\mathrm{bh}}$ buharlaştırıcı yardımıyla ORÇ'ye giren 1s1 miktarıdır.

$\dot{\mathrm{Q}}_{\mathrm{bh}}=\dot{\mathrm{m}}_{5}\left(\mathrm{~h}_{6}-\mathrm{h}_{5}\right)$

Burada, $\dot{\mathrm{m}}_{5}, \mathrm{~h}_{6}$ ve $\mathrm{h}_{5}$ sırasıyla, çalışılan sıvının kütle akış hızı, 5 ve 6 noktalarının entalpisidir.

Çizelge 1, Çizelge 2, Çizelge 3 ve Çizelge 4'de, Farklı aylar için sistemde kullanılan sıvıların sıcaklıkları, basıncı ve kütle akış hızı verilmiștir. $\mathrm{Bu}$ değerler termodinamik hesaplamaları yapmak için EES'te kullanılmıştır. Bu sistemde ORÇ'ye giriș sıcaklığı ve çevre sıcaklığı aydan aya değişmektedir. Diğer değerler her ay için aşağıdaki gibi verilmiştir.

Çizelge 1. Sistemin termodinamik parametreleri (Haziran ayı için)

\begin{tabular}{|c|l|c|c|c|}
\hline No & Siv1 & $\begin{array}{c}\text { Sicaklık } \\
\left({ }^{\circ} \mathrm{C}\right)\end{array}$ & $\begin{array}{c}\text { Basınç } \\
(\mathrm{kPa})\end{array}$ & $\begin{array}{c}\text { Kütle ak1ş } \\
\text { h1z1 }(\mathrm{kg} / \mathrm{s})\end{array}$ \\
\hline 0 & $\mathrm{Hava}$ & 25,5 & 101.3 & - \\
\hline 1 & $\mathrm{H}_{2} \mathrm{O}$ & 35 & 150 & 0,040 \\
\hline 2 & $\mathrm{H}_{2} \mathrm{O}$ & 53,48 & 150 & 0,040 \\
\hline 3 & $\mathrm{H}_{2} \mathrm{O}$ & 53,48 & 150 & 0,040 \\
\hline 4 & $\mathrm{H}_{2} \mathrm{O}$ & 36 & 150 & 0,040 \\
\hline 6 & İzobütan & 53 & 2000 & 0,010 \\
\hline 7 & İzobütan & 35 & 1750 & 0,010 \\
\hline 8 & İzobütan & 32 & 1750 & 0,010 \\
\hline 5 & İzobütan & 30 & 2000 & 0,010 \\
\hline
\end{tabular}

Çizelge 2. Sistemin termodinamik parametreleri (Temmuz ayı için)

\begin{tabular}{|c|l|c|c|c|}
\hline No & Siv1 & $\begin{array}{c}\text { Sicaklık } \\
\left({ }^{\circ} \mathrm{C}\right)\end{array}$ & $\begin{array}{c}\text { Basınç } \\
(\mathrm{kPa})\end{array}$ & $\begin{array}{c}\text { Kütle akış } \\
\text { hız1 }(\mathrm{kg} / \mathrm{s})\end{array}$ \\
\hline 0 & Hava & 28 & 101.3 & - \\
\hline 1 & $\mathrm{H}_{2} \mathrm{O}$ & 35 & 150 & 0,040 \\
\hline 2 & $\mathrm{H}_{2} \mathrm{O}$ & 54,08 & 150 & 0,040 \\
\hline 3 & $\mathrm{H}_{2} \mathrm{O}$ & 54,08 & 150 & 0,040 \\
\hline 4 & $\mathrm{H}_{2} \mathrm{O}$ & 36 & 150 & 0,040 \\
\hline 6 & İzobütan & 53,5 & 2000 & 0,010 \\
\hline 7 & İzobütan & 35 & 1750 & 0,010 \\
\hline 8 & İzobütan & 32 & 1750 & 0,010 \\
\hline 5 & İzobütan & 30 & 2000 & 0,010 \\
\hline
\end{tabular}

Çizelge 3. Sistemin termodinamik parametreleri (Ağustos ayı için)

\begin{tabular}{|c|l|c|c|c|}
\hline No & Siv1 & $\begin{array}{c}\text { Sicaklık } \\
\left({ }^{\circ} \mathrm{C}\right)\end{array}$ & $\begin{array}{c}\text { Basınç } \\
(\mathrm{kPa})\end{array}$ & $\begin{array}{c}\text { Kütle ak1Ş } \\
\text { hızı }(\mathrm{kg} / \mathrm{s})\end{array}$ \\
\hline 0 & $\mathrm{Hava}$ & 28,4 & 101.3 & - \\
\hline 1 & $\mathrm{H}_{2} \mathrm{O}$ & 35 & 150 & 0,040 \\
\hline 2 & $\mathrm{H}_{2} \mathrm{O}$ & 54,75 & 150 & 0,040 \\
\hline 3 & $\mathrm{H}_{2} \mathrm{O}$ & 54,75 & 150 & 0,040 \\
\hline 4 & $\mathrm{H}_{2} \mathrm{O}$ & 36 & 150 & 0,040 \\
\hline 6 & İzobütan & 54,25 & 2000 & 0,010 \\
\hline 7 & İzobütan & 35 & 1750 & 0,010 \\
\hline 8 & İzobütan & 32 & 1750 & 0,010 \\
\hline 5 & İzobütan & 30 & 2000 & 0,010 \\
\hline
\end{tabular}

Çizelge 4. Sistemin termodinamik parametreleri (Eylül ayı için)

\begin{tabular}{|c|l|c|c|c|}
\hline No & Siv1 & $\begin{array}{c}\text { Sicaklık } \\
\left({ }^{\circ} \mathrm{C}\right)\end{array}$ & $\begin{array}{c}\text { Basınç } \\
(\mathrm{kPa})\end{array}$ & $\begin{array}{c}\text { Kütle ak1ş } \\
\text { hız1 }(\mathrm{kg} / \mathrm{s})\end{array}$ \\
\hline 0 & $\mathrm{Hava}$ & 25,8 & 101,3 & - \\
\hline 1 & $\mathrm{H}_{2} \mathrm{O}$ & 35 & 150 & 0,040 \\
\hline 2 & $\mathrm{H}_{2} \mathrm{O}$ & 52,70 & 150 & 0,040 \\
\hline 3 & $\mathrm{H}_{2} \mathrm{O}$ & 52,70 & 150 & 0,040 \\
\hline 4 & $\mathrm{H}_{2} \mathrm{O}$ & 36 & 150 & 0,040 \\
\hline 6 & İzobütan & 52,2 & 2000 & 0,010 \\
\hline 7 & İzobütan & 35 & 1750 & 0,010 \\
\hline 8 & İzobütan & 32 & 1750 & 0,010 \\
\hline 5 & İzobütan & 30 & 2000 & 0,010 \\
\hline
\end{tabular}

\section{BULGULAR VE TARTIŞMALAR}

Bu çalışmada, sistemin termodinamik analizini yapmak için havuzun yüzeyine gelen güneş enerjisi bilinmelidir. Şekil 2'de aylara göre toplam yatay yüzeye gelen güneş enerjisi verilmiştir. $\mathrm{Bu}$ veriler Adana Meteoroloji İstasyonundan elde edilmiştir. Şekil 2'de görüldüğü gibi, Adana için 
yatay yüzeye gelen güneş enerjisi en fazla Haziran, Temmuz, Ağustos ve Eylül aylarında olup sırasıyla $756 \mathrm{MJ} / \mathrm{m}^{2}, 792 \mathrm{MJ} / \mathrm{m}^{2}, 735 \mathrm{MJ} / \mathrm{m}^{2}$ ve $513 \mathrm{MJ} / \mathrm{m}^{2}$ dir. Gelen güneş enerjisi miktarına bağlı olarak güneş havuzunun depolama bölgesinin de en yüksek sıcaklıklara ulaştığı görülmüştür.

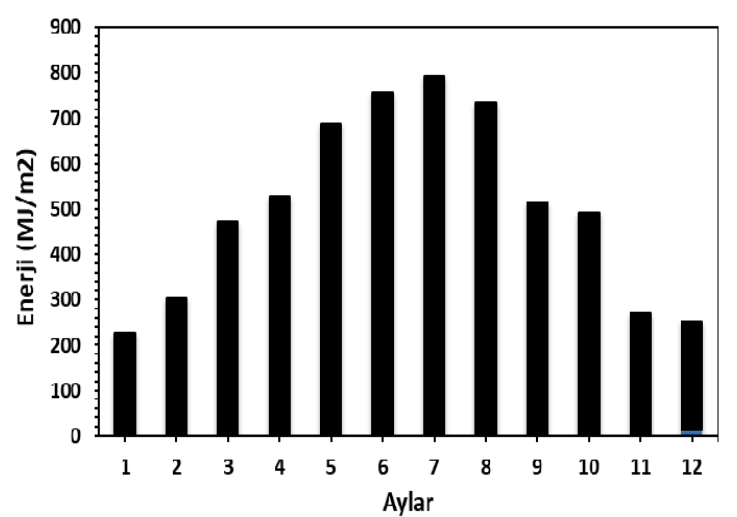

Şekil 2. Adana için aylara göre toplam gelen güneş enerjisi değişimi

Şekil 2'de tüm yıl için yatay yüzeye gelen güneş enerjisinin aylara göre değişimi incelendiğinden yüzeye gelen güneş enerjinin en yüksek olduğu ay Temmuz ve en düşük olduğu ay ise Ocak olduğu görülmektedir. Güneş havuzunun en verimli olduğu aylar Haziran, Temmuz ve Ağustos ayıdır. Ancak Eylül ayı güneş havuzunun 1S1 depolama veriminin iyi olduğu için bu çalışmada Eylül ayıda kullanılmıştır [14].

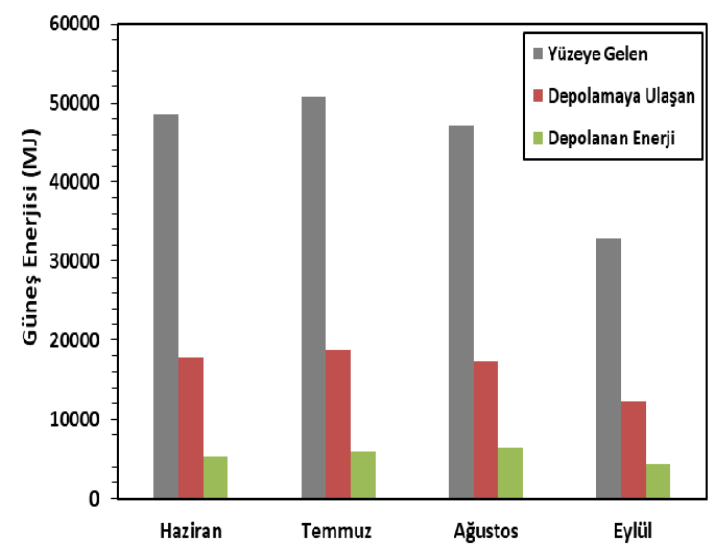

Şekil 3. Farklı aylarda güneş havuzuna gelen güneş enerjisinin değişimi
Şekil 3'te Haziran, Temmuz, Ağustos ve Eylül ayları için güneş enerjisinin havuzun yüzeyinden girerek depolama bölgesine geldikten sonra depolama bölgesine ulaştıktan sonra ne kadar enerjinin depolandığı verilmektedir. Haziran, Temmuz, Ağustos ve Eylül ayında güneş havuzunun yüzeyine gelen enerji sirasiyla 48410 MJ, 50730 MJ, 47071 MJ ve 32889 MJ'dür. Daha sonra güneş enerjisi yüzeyden girerek ÜYB ve YB geçerken bir kısmı soğurularak DB'ye ulaşır. Haziran, Temmuz, Ağustos ve Eylül ayında depolama bölgesine ulaşan güneş enerjisi sırasıyla 17911 MJ, 18770 MJ, 17416 MJ ve 12168 MJ'dür. En sonunda çevresel şartlardan ve iletim kayıplarından dolayı bir miktar 1S1 kayb1 gerçekleşerek depolama bölgesine ulaşan güneş enerjisi 1sı enerjisine dönüştürülür ve DB'de depolanır. Haziran, Temmuz, Ağustos ve Eylül ayında depolama bölgesinde depolanan 1s1 enerjisi sirasiyla 5199 MJ, 5865 MJ, 6487 MJ ve 4267 MJ'dür. Ağustos ayının diğer aylardan daha yüksek 1sı enerjisi depolamasının sebebi: Güneş havuzu en yüksek verime bu ayda ulaştığından daha fazla isı enerjisi depolanır.

Şekil 4'te Haziran, Temmuz, Ağustos ve Eylül ayları için ORÇ yardımıyla üretilen elektrik enerjisi verilmektedir. $\mathrm{Bu}$ aylarda, ORÇ'de üretilen elektrik enerjisi sirasıyla 143,2 MJ, 156,2 MJ, 168,5 MJ ve 130,5 MJ'dür. ORÇ’de en iyi elektrik üretimi depolanan enerjinin en fazla olduğu Ağustos ayında gerçekleşmiştir.

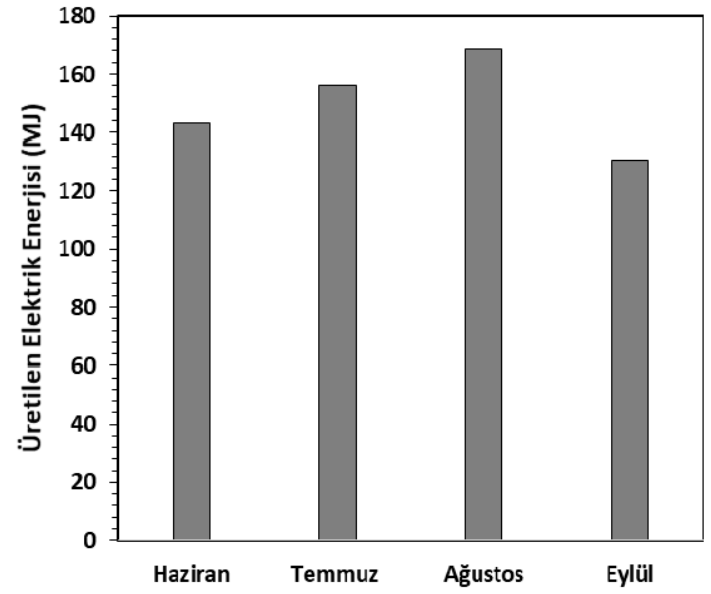

Şekil 4. Farklı aylar için ORÇ’nin elektrik üretimi 


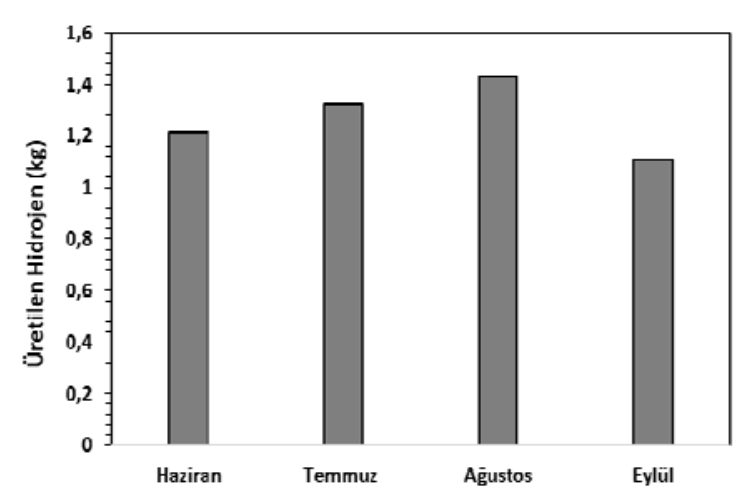

Şekil 5. Farklı aylarda üretilen hidrojen enerjisi

Şekil 5'de Haziran, Temmuz, Ağustos ve Eylül aylarında üretilen hidrojen miktarı görünmektedir. Elektroliz sisteminde $1 \mathrm{~kg}$ hidrojen üretmek için $32,7 \mathrm{kWh}$ enerji gerekmektedir. Bu enerji 1 saatte 117,72 MJ enerjiye denktir [22]. Haziran, Temmuz, Ağustos ve Eylül'de sirasıyla 1,216 kg, $1,316 \mathrm{~kg}, 1,431 \mathrm{~kg}$ ve $1,108 \mathrm{~kg}$ olarak elektroliz sistemde hidrojen üretilmiştir.

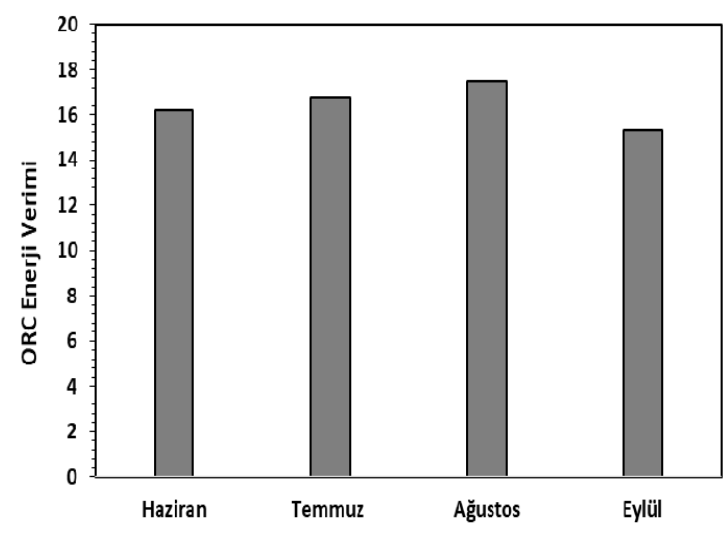

Şekil 6. Farklı aylar için ORÇ’nin enerji verimi

Şekil 6. Haziran, Temmuz, Ağustos ve Eylül'de ORÇ'nin enerji verimi denklem 8 ' den yararlanarak bulunmuştur. Haziran, Temmuz, Ağustos ve Eylül ayında ORÇ'nin enerji verimi ise sırasıyla, $\% 16,20, \% 16,73, \% 17,47$ ve $\% 15,32$ olarak bulunmuştur. ORÇ'nin en verimli çalıştığı ay Ağustos iken, en düşük verimle çalıştığ 1 ay ise Eylül ayıdır.

\section{SONUÇ}

$\mathrm{Bu}$ çalışmada, boyutları $1,5 \times 8 \times 8 \mathrm{~m}^{3}$ dikdörtgen prizma şeklinde bir güneş havuzunun, Organik Rankine Döngüsü (ORÇ) ve elektroliz sistemi ile birbirine bütünleşmiş bir sisteminin modeli başarılı bir şekilde analiz edilmiştir. $\mathrm{Bu}$ sistem, güneş havuzunun depolama bölgesinde bulunan 1s1 enerjisini bir pompa yardımıyla ORÇ’ye göndererek sistemin çalışması sağlanmıştır Böylece düşük sıcaklıklarda elektrik ve hidrojen üretilmeye başlanmıştır. Sistemin analizi için EES benzetim programı başarılı bir şekilde çalıştırılmıştır. Analizler güneş havuzunun depolama bölgesi sıcaklığının en yüksek değerlere ulaştığı Haziran, Temmuz, Ağustos ve Eylül ayları için ayrı ayrı olarak yapılmıştır. Sistemde, Adana'da ORÇ yardımıyla Haziran, Temmuz, Ağustos ve Eylül ayları için 143,2 MJ, 156,2 MJ, $168,5 \mathrm{MJ}$ ve 130,5 MJ elektrik enerjisi üretilmiştir. Böyle bir sistemde ORÇ’nin enerji verimi ise sirasıly, $\% 16,20, \% 16,73,17,47$ ve $\% 15,32$ olarak bulunmuştur. Üretilen elektrik ile elektroliz sistemi aracılığıyla, Haziran, Temmuz, Ağustos ve Eylül ayı için sırasıyla, $1,216 \mathrm{~kg}, 1,326 \mathrm{~kg}, 1,431 \mathrm{~kg}$ ve $1,108 \mathrm{~kg}$ hidrojen üretilebileceği görülmüştür. Sonuç olarak, güneş havuzunun sıcaklığının en yüksek olduğu Ağustos ayında maksimum oranda elektrik ve hidrojen üretilmiştir. Böyle bir bütünleşik sistem sayesinden güneş enerjisi, başarılı bir şekilde depolanabilir bir enerji kaynağı olan hidrojen gazına dönüştürülmüştür. Benzer şekilde hidrojen gazı da yakıt pili ile yeniden elektriğe ve dolayısı ile 1 sı ve ışığa dönüştürülebilir. Böylece, bu sistem yenilenebilir enerji kaynağı ile çalıştığından, zararlı atık üretmez ve çevreye zarar vermediği için çevreci bir sistemdir. Böyle sistemler çoğaldıkça dünya daha uzun süre yaşanabilir bir yer olmaya devam edecektir.

\section{KAYNAKLAR}

1. Öztürk, M., Özek, N., Berkama, B., 2012. Comparison of Some Existing Models for Estimating Monthly Average Daily Global Solar Radiation for Isparta, Pamukkale 
University Journal of Engineering Sciences, $18,13-27$.

2. Karakilcik, M., Dincer, I., Rosen, M., 2006. Performance Investigation of a Solar Pond, Applied Thermal Engineering, 26, 727-735.

3. Abdullah, A.A., Lindsay, K.A., AbdelGawad, A.F., 2016. Construction of Sustainable Heat Extraction System and a New Scheme of Temperature Measurement in an Experimental Solar Pond for Performance Enhancement, Solar Energy, 130, 10-24.

4. Date, A., Yaakob, Y., Date, A., Krishnapillai, S., Akbarzadeh, A., 2013. Heat Extraction from Non-Convective and Lower Convective Zones of the Solar Pond: A Transient Study, Solar Energy, 97, 517-528.

5. Ding, L.C., Akbarzadeh, A., Tan, L., 2018. A Review of Power Generation with Thermoelectric System and its Alternative with Solar Ponds, Renewable and Sustainable Energy Reviews, 81, 799-812.

6. Bertrand F., Tchanche, B.F., Lambrinos, G., Frangoudakis, A., Papadakis, G., 2011. LowGrade Heat Conversion Into Power Using Organic Rankine Cycles-A Review of Various Applications, Renewable and Sustainable Energy Reviews, 15, 3963-3979.

7. Erden, M., Karakilcik, M., Dincer, I., 2017. Performance Investigation of Hydrogen Production by the Flat-Plate Collectors Assisted by a Solar Pond, International Journal of Hydrogen Energy, 42, 2522-2529.

8. Karapekmez, A., Dincer, I., 2018. Modelling of Hydrogen Production from Hydrogen Sulfide In Geothermal Power Plants, International Journal of Hydrogen Energy 43, 10569-10579.

9. Dincer, I., Acar, C., 2018. Smart Energy Solutions with Hydrogen Options, International Journal of Hydrogen Energy 43, 8579-8599.

10. Yüksel, Y.E., Öztürk, M., 2016. Thermodynamic Analysis of Integrated WindSolar-Hydrogen System for Residential Applications, El-Cezerî Journal of Science and Engineering, 3, 401-416.

11. Yüksel, Y.E., Öztürk, M., 2015. Thermodynamic Analysis of an Integrated Solar-based Chemical Reactor System for
Hydrogen Production, El-Cezerî Journal of Science and Engineering, 2, 19-27.

12. Ozturk, M., Dincer, I., 2013. Thermodynamic Assessment of an Integrated Solar Power Tower and Coal Gasification System for MultiGeneration Purposes, Energy Conversion and Management, 76, 1061-1072.

13. Bozkurt, I., Karakilcik, M., 2012. The Daily Performance of a Solar Pond Integrated with Solar Collectors. Solar Energy, 86, 1611-1620.

14. Bozkurt, I., Karakilcik, M., 2015. The Effect of Sunny Area Ratios on the Thermal Performance of Solar Ponds. Energy Conversion and Management, 91, 323-332.

15. Karakilcik, M., Dincer, I., Bozkurt, I., Atiz, A., 2013. Performance Assessment of a Solar Pond With and Without Shading Effect, Energy Conversion and Management, 65, 98-107.

16. Karakilcik, M., 2016. The Effect on Performance of the Salt Gradient Zone of the Solar Pond Çukurova University Journal of the Faculty of Engineering and Architecture, 31, 391-400.

17. Cengel, Y.A., 2006. Heat and Mass Transfer, Third Edition, Mc Graw Hill.

18. Quoilin, S., Den Broek, M.V., Declaye, S., Dewallef, P., Lemort, V., 2013. Technoeconomic survey of Organic Rankine Cycle (ORC) systems, Renewable and Sustainable Energy Reviews, 22, 168-186.

19. Wang, J., Yan, Z., Wang, M., Maa, S., Dai Y., 2013. Thermodynamic Analysis and Optimization of an (Organic Rankine Cycle) ORC Using Low Grade Heat Source, Energy 49, 356-365.

20. Tchanche, B.F., Papadakis, G., Lambrinos, G., Frangoudakis, A., 2009. Fluid Selection for A Low-Temperature Solar Organic Rankine Cycle, Applied Thermal Engineering 29, 2468-2476.

21. Ozturk, M., Dincer, I., 2013. Thermodynamic Analysis of a Solar-Based Multi-Generation System with Hydrogen Production, Applied Thermal Engineering, 51, 1235-1244.

22. Yılmaz, C., Kanoğlu, M., Bolattürk, A., 2011. Jeotermal Enerji ile Hidrojen Üretilmesi ve Sıvılaştırılması, X.Ulusal Tesisat Mühendisliği Kongresi, İzmir. 